\title{
Natural Structural Motifs that Suppress Peptide Ion Fragmentation after Electron Capture
}

\author{
Wai Yi Kelly Chan and Tak Wah Dominic Chan \\ Department of Chemistry, The Chinese University of Hong Kong, Shatin, N.T. Hong Kong SAR, China
}

Series of doubly and triply protonated diarginated peptide molecules with different number of glutamic acid (E) and asparagine $(N)$ residues were analyzed under ECD conditions. ECD spectra of doubly-protonated peptides show a strong dependence on the number of $\mathrm{E}$ and $\mathrm{N}$ residues. Both the backbone cleavages and hydrogen radical $\left(\mathrm{H}^{*}\right)$ loss from the charge-reduced precursor ions $\left([\mathrm{M}+2 \mathrm{H}]^{+}\right.$) were suppressed as the number of $\mathrm{E}$ and $\mathrm{N}$ residues increases. A strong inhibition of the backbone cleavages and $\mathrm{H}^{\bullet}$ loss from $[\mathrm{M}+2 \mathrm{H}]^{+\bullet}$ was found for peptides with $6 \mathrm{E}$ residues (or $4 \mathrm{E}+2 \mathrm{~N}$ residues). The results obtained using these model peptides were re-confirmed by analyzing $\mathrm{N}$-arginated Fibrinopeptide-B (i.e., REGVNDNEEGFFSAR). In contrast to the $\mathrm{N}$-arginated peptide, ECD of the doubly-protonated Fibrinopeptide-B and its analogues show extensive backbone cleavages leading to series of $c$ - and $z$-ions ( $\sim 80 \%$ sequence coverage). Based on these results, it is believed that peptide ions with all surplus protons sequestered in arginine-residues would show enhanced stability under ECD conditions as the number of acid-residue increases. The suppression of backbone cleavages and $\mathrm{H}^{\bullet}$ loss from $[\mathrm{M}+2 \mathrm{H}]^{+}{ }^{\bullet}$ are presumably attributed to the low reactivity of the charge-reduced precursor ions. One of the possible hypothesis is that diarginated E-rich peptides may contain hydrogen bonds between carbonyl oxygen of E side chains and backbone amide hydrogen. These hydrogen bonds would provide extra stabilization for $\left[\mathrm{M}+2 \mathrm{H}^{+} \cdot \bullet\right.$. This is the first demonstration of natural structural motifs in peptides that would inhibit the backbone fragmentation of the charge-reduced peptide ions under ECD conditions. (J Am Soc Mass Spectrom 2010, 21, 1235-1244) @ 2010 Published by Elsevier Inc. on behalf of American Society for Mass Spectrometry

$\mathrm{E}$ lectron capture dissociation (ECD) is an important tandem mass spectrometry (MS/MS) tool for sequencing multiply-charged peptides/proteins [1-4]. ECD also plays a useful role in characterization and localization of post-translational modifications (PTMs) as it preserves labile PTMs in protein [5-7] while cleaving the protein backbone to give series of specific fragment ions. This is in contrast with that of conventional slow-heating ion dissociation methods $[8$, 9], such as collision induced dissociation (CID) [10-12] and infrared multiproton dissociation (IRMPD) [13]. ECD involves the reaction between multiply-charged ions and low-energy electrons. Besides the formation of the charge-reduced precursor ions, $[\mathrm{M}+\mathrm{nH}]^{(\mathrm{n}-1)+} \bullet$, the recombination energy released might provide enough energy to cause backbone $\mathrm{N}-\mathrm{C}_{\alpha}$ cleavages producing series of $c$ or $z^{\bullet}$ ions and to a lesser extent series of $a^{\bullet}$ or $\mathrm{y}$ ions. Other ECD events include the elimination of (1) a $\mathrm{H}^{\bullet}$ to form $[\mathrm{M}+(\mathrm{n}-1) \mathrm{H}]^{(\mathrm{n}-1)+}$, and (2) amino acid side chains from $\mathrm{z}^{\bullet}$ ions and $/$ or $[\mathrm{M}+\mathrm{nH}]^{(\mathrm{n}-1)+} \cdot$. Cleavages in ECD are nonspecific [14], and the relative propensi-

Address reprint requests to Dr. T.-W. Dominic Chan, Department of Chemistry, Chinese University of Hong Kong, Shatin. N.T., Hong Kong SAR. E-mail: twdchan@cuhk.edu.hk ties for dissociation of various amino acid residues were found to fall in a narrow range. Because of the ring-type structure, only fragment ions resulting from the backbone cleavages at the $\mathrm{N}$-terminal side of proline $(\mathrm{P})$ were suppressed [15].

The importance of radical in charge-reduced precursor ion in ECD was investigated by synthetically incorporating single and multiple radical trap, spin trap, and charge tag moieties in model peptides. In radical trap experiments, Belyayev et al. [16] attached coumarin labels onto the N-terminal amino group (or/and lysine side chain) and demonstrated that the presence of a radical trap in a peptide ion could inhibit backbone fragmentation under typical ECD conditions. Similar observations were also made by Jones and coworkers using 2-(4'-carboxypyrid-2'-yl)-4-carboxamide group (pepy) [17] as spin trap label. In fixed charge experiments, $\mathrm{Li}$ et al. attached 2,4,6-trimethylpyridinium (TMP) [18] to the N-terminal amino group (or/and lysine side chain) of some model peptides and showed that the usual backbone cleavage fragments were suppressed and some label-related neutral losses from the reduced precursor ions were found. Chamot-Rooke and coworkers obtained similar results using tris-(2,4,6trimethoxyphenyl)phosphonium-methylenecarboxamido 
(TMPP-ac) groups [19] as fixed charge carriers. ECD at low-temperature (e.g., $86 \mathrm{~K}$ ) of linear peptide and cyclic peptide would also dramatically reduce the number of backbone fragments [20]. The authors attributed the reduction of backbone fragments to the decrease in number of conformers at low-temperature. Hongo et al. found that backbone cleavages were suppressed in ECD of triantennary complex-type N-glycosylated peptides [21a]. The suppression of backbone cleavages were tentatively attributed to the presence of carbamoylmethylated cysteine residue in the peptide. The carbamoylmethylated cysteine might serve as a 'radical trap' and glycopeptides with both cysteine residue and NeuNAc were found to give very few or no backbone fragments. More recently, Sohn and coworkers [21b] investigated the ECD behavior of electron affinity tuned peptides. It was demonstrated that typical ECD or ETD backbone fragmentations could be completely inhibited in peptides with substituent tags having EA over $1.00 \mathrm{eV}$.

To secure proper spectral interpretation and further improve the analytical utilities of ECD methods, it is important to identify factors that influence the dissociation efficiency and pathways of peptide ions, especially the role of radical in the charge-reduced precursor ion during dissociation. In this study, we provide evidence to show that certain natural structural motifs in proteins could inhibit the backbone fragmentation of the charge-reduced peptide ions under ECD conditions. Together with conformational search, a hypothesis based on the interaction between the side chains of $\mathrm{E}$ (or $\mathrm{N})$ and the backbone amide hydrogen was used to account for the extra-stability of the charge-reduced precursor ions. Glutamic acid (E) and asparagine (N) residues were used in this study because a bioactive peptide, namely fibrinopeptide $B$, could be found as an analogue system for demonstrating the generalization of the suppression effect. It is believed that similar observations should be obtained by using aspartic acid (D) and glutamine (Q).

\section{Experimental}

\section{Materials}

A series of model peptides with sequence RGEGEGEGEGEGEGR，RGEGGEGGGEGGEGR，RGGEGGGEGGGEGGR, RGGGGEGGGEGGGGR, RGEGNGEGEGNGEGR, and RGEGGNGGGNGGEGR were purchased from Peptron Inc., (Daejeon, South Korea) and were used without further purification. Fibrinopeptide-B (EGVNDNEEGFFSAR) and its analogue, i.e., REGVNDNEEGFFSA, and REGVNDNEEGFFSAR, were synthesized in-house using a Personal Synthesizer (Peti-Syzer model PSS-510; HiPep Laboratories, Kyoto, Japan) and were used without further purification. Standard Fmoc synthesis procedures were employed [22-24]. All reagents used for peptide synthesis were obtained from Sigma and Aldrich (St. Louis, MO, USA), LC Science
(Houston, TX, USA) and Advanced ChemTech (Creo Salus Inc., Louisville, KY, USA). All samples were prepared at concentration of $2.5 \times 10^{-5} \mathrm{M}$ in 1:1 water: methanol (Labscan Ltd., Bangkok, Thailand) with $3 \%-5 \%$ acetic acid (Riedel-de Haen, Seelze, Germany).

\section{Instrumentation}

All ECD experiments were conducted by using a 4.7 Tesla Fourier transform ion cyclotron resonance mass spectrometer (FT-ICR MS) (APEX I; Bruker Instrument Inc., Boston, MA, USA). The computer system and associated electronics were upgrade to APEX III. This instrument was equipped with a standard commercially available external electrospray ion source (Analytica, Brandford, CT, USA). The ESI ion source was modified to adopt a homemade nanospray [25]. Sample solution $(10-15 \mu \mathrm{L})$ was loaded into a fused glass capillary tip and was electrically grounded using a 10 $\mu \mathrm{m}$ gold-plated tungsten wire. The nanospray tip was positioned to 1 to $2 \mathrm{~mm}$ in front of a dielectric capillary. Spraying of the sample solution was induced by floating the front metal cap of the dielectric capillary to -800 to $-1000 \mathrm{~V}$. A steam of heated dry nitrogen gas $\left(\sim 275^{\circ} \mathrm{C}\right)$ was used to warm up the dielectric capillary and to assist the desolvation of the analyte ions from the sprayed droplets. Doubly-protonated and triplyprotonated peptides were produced and accumulated in a hexapole ion guide for $1 \mathrm{~s}$ before transferring to the Infinity Cell [26]. Ion transmission from the external source into the trapping cell was achieved by using the standard electrostatic lens system. Sidekick ion accumulation method was used to facilitate the ion trapping process. In all experiments, static trapping potential of $1.0 \mathrm{~V}$ was used. For experiments involving triplyprotonated peptides, the precursor ion intensities were generally too low to generate good ECD spectra. To boost up the precursor ion intensity, multiple-ion filling (MIF) method was adopted [27]. In a typical MIF pulse sequence, argon gas was pulsed from a pressureregulated cylinder ( $\sim 0.35$ bar) into the analyzer region using a solenoid pulse-valve with a fixed duration of $1200 \mu$ s and the cell pressure was raised from $2 \times 10^{-9}$ Torr up to $5 \times 10^{-7}$ Torr. The relative high-pressure in the trapped ion cell can effectively remove the excess z-axial kinetic energy of the nanospray derived ions and prevent substantial loss of trapped ions during the admission of another pulse of ions.

For ECD experiments, the precursor ion was isolated by over-excitation of all the unwanted ions. Standard electrically-heated filament source was used to produce pulses of electrons. The filament was made of rhenium ribbon and was fixed at a distance of $108 \mathrm{~mm}$ from the rear end of the Infinity cell. Details of the geometry of the filament source have been previously described [28]. Typical experimental conditions were 3.2 A filament heating current, $4.0 \mathrm{~V}$ average filament bias voltage and $300 \mathrm{~ms}$ electron irradiation time. All ECD mass spectra were acquired in broadband mode using $128 \mathrm{k}$ 
data points. Thirty scans were summed to improve the signal-to-noise ratios. All time-domain signals were zero-filled once before Fourier Transformation. Initial calibration of the instrument was performed by using a peptide mixture containing LGF, angiotension II, and melittin.

\section{Calculations}

The Merck molecular force fields (MMFFs) and conformational search (low mode conformational search, LMCS) were used to predict the low-energy conformers using MacroModel program (ver. 5; Schrodinger Inc., Portland, OR, USA). In general, truncated NewtonRaphson conjugate gradient (TNCG) was used to performed energy minimization. The low-mode conforma- tional search was conducted using Monte Carlo [29] method with a random variation of all bonds [30]. Low-energy conformers were found in 5000 steps. Only structures with energies within $50 \mathrm{kJmol}^{-1}$ from the lowest-energy structure were stored. From the results of the initial search, the lowest-energy structure and up to 10 structurally different conformers were used as starting geometries for new 5000 steps conformational searches. Energies of all structures found in these conformational searches were aligned. Low-energy conformers that are within $15 \mathrm{kJmol}^{-1}$ from the lowest energy conformer were then used to compute the hydrogen-bonding pattern of the peptide backbone. The relative contribution of hydrogen-bonding from each low-energy conformer was calculated using Boltzmann distribution. The overall distribution of the

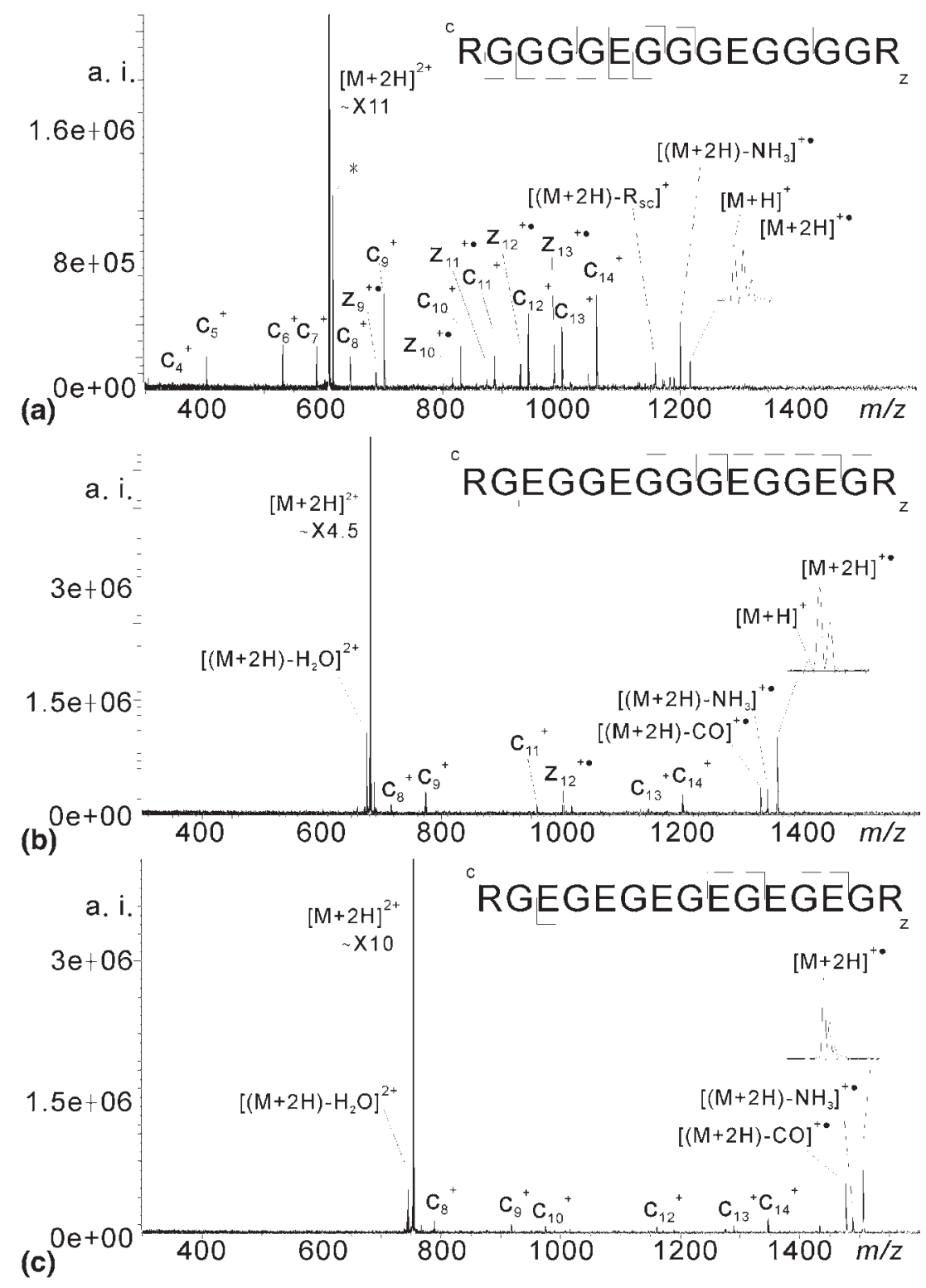

Figure 1. Typical ECD spectra of $[\mathrm{M}+2 \mathrm{H}]^{2+}$ where $\mathrm{M}$ is (a) RGGGGEGGGEGGGGR, (b) RGEGGEGGGEGGEGR, and (c) RGEGEGEGEGEGEGR. 
hydrogen bonds was obtained by adding up the relative abundance of hydrogen-bonding formed at backbone amide linkages contributed by the low-energy conformers.

\section{Results and Discussion}

\section{General Features of ECD Spectra of Doubly Protonated Peptides}

Figure 1(a-c) show typical ECD spectra of doublyprotonated diarginated peptides, $[\mathrm{M}+2 \mathrm{H}]^{2+}$, with the sequences of RGGGGEGGGEGGGGR, RGEGGEGGGEGGEGR, and RGEGEGEGEGEGEGR, respectively. Typical ECD induced fragments, i.e., $\mathrm{C}_{4}{ }^{+}$to $\mathrm{C}_{14}{ }^{+}, \mathrm{z}_{8}{ }^{+}$to $\mathrm{z}_{14}{ }^{+}$, and peaks corresponding to charge-reduced precursor ion $\left([\mathrm{M}+2 \mathrm{H}]^{+}{ }^{\bullet}\right)$ were observed. Attributable to low stability of odd-electron species, $\mathrm{z}_{\mathrm{n}}{ }^{+}$were generally weaker in intensities than even-electron species, $\mathrm{c}_{\mathrm{n}}{ }^{+}$ [31]. Besides the usual $c$ - and $z$-ions, $[\mathrm{c}-\mathrm{H}]^{\circ}$ and $[\mathrm{z}+$ $\mathrm{H}]$ species and cleavage products related to the loss of $\mathrm{NH}_{3}, \mathrm{CO}$, side-chain of glutamic acid (E), and/or arginine $(\mathrm{R})$ from the reduced precursor ions, $[\mathrm{M}+2 \mathrm{H}]^{+}{ }^{\bullet}$, were also observed in these ECD spectra. From Figure 1 , both the number and intensities of $c$ - and $z$-ions were found to decrease progressively as the number of $\mathrm{E}$ residues increases. In addition, hydrogen radical $\left(\mathrm{H}^{*}\right)$ loss from $[\mathrm{M}+2 \mathrm{H}]^{+}{ }^{\bullet}$ was found to decrease dramatically with increasing number of $\mathrm{E}$ in the diarginated model peptides. Comparing to Figure 1a and b, high abundance of $[\mathrm{M}+2 \mathrm{H}]^{+}$in Figure 1c provides evidence for successful electron capture event and suppression of backbone cleavages. Figure 2a shows the percentage of $\mathrm{H}^{\bullet}$ loss from $[\mathrm{M}+2 \mathrm{H}]^{+}$of diarginated model peptides studied. Isotopic contribution of the charge-reduced precursor ion had been considered in the calculation. Measurement of error was obtained by three replicate experiments of RGEGNGEGEGNGEGR and the error of percentage of $\mathrm{H}^{\bullet}$ loss from $[\mathrm{M}+2 \mathrm{H}]^{+}$ was found to be $\pm 0.6 \%$. Since the error was significantly smaller than the differences between data points, no further estimation of measurement of error was performed on other samples. In Figure 2a, substantial loss of $\mathrm{H}^{\bullet}$ from $[\mathrm{M}+2 \mathrm{H}]^{+\bullet}$ was observed when $\mathrm{E}$ to $\mathrm{R}$ ratio in peptide equals to $1: 1$. The percentage of $\mathrm{H}^{\bullet}$ loss decreases progressively from $73 \%$ to $0 \%$ when E:R ratio increases from 1:1 to 3:1. No [M+ H] ${ }^{+}$was observed in ECD of doubly-protonated peptide with $6 \mathrm{E}$ implies that no $\mathrm{H}^{\bullet}$ was loss from the charge-reduced precursor ions. Since the extent of $\mathrm{H}^{\bullet}$ loss from the reduced precursor ion was lower in cases of $6 \mathrm{E}$ and $4 \mathrm{E}$ than the corresponding $(4 \mathrm{E}+2 \mathrm{~N})$ and $(2 \mathrm{E}+2 \mathrm{~N})$, the impact of $\mathrm{E}$ on the suppression of cleavage was said to be greater than that of $\mathrm{N}$.

Apart from $\mathrm{H}^{\bullet}$ loss from $[\mathrm{M}+2 \mathrm{H}]^{+}$, the number and intensities of backbone fragments were found to decrease as the number of $E$ residues increases. To investigate the suppression effect of backbone cleavages in doublycharged precursor ions of diarginated model peptides,
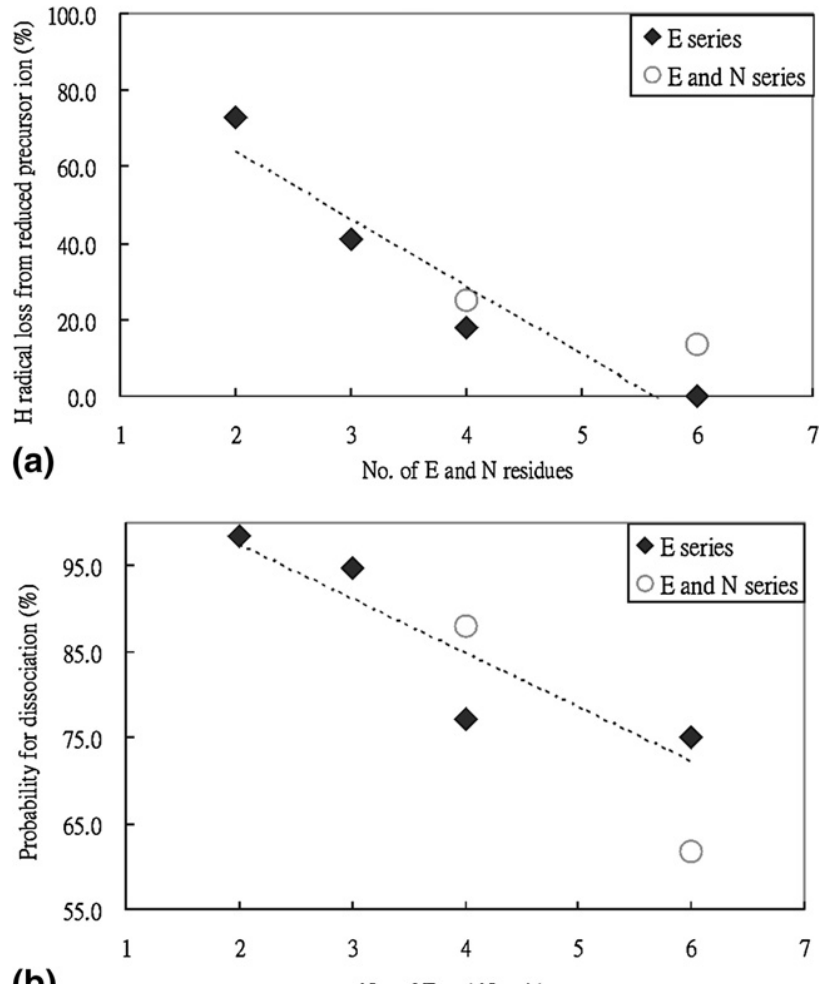

(b)

No. of $\mathrm{E}$ and $\mathrm{N}$ residues

Figure 2. (a) Percentage of $\mathrm{H}^{\bullet}$ loss from $[\mathrm{M}+2 \mathrm{H}]^{+\bullet}$ of diarginated model peptides, (b) Probability for dissociation in ECD of $[\mathrm{M}+2 \mathrm{H}]^{2+}$ of diarginated model peptides.

probability for dissociation in ECD ( $\left.E C D_{\text {Pro_Disso }}\right)$ of these peptides were calculated by eq 1 ,

$$
\begin{aligned}
& E C D_{\text {Pro_Disso }} \\
& =\frac{\left.\sum I_{\left[E C D \_ \text {Fragments }\right]}\right]}{\sum I_{\left[E C D \_ \text {Fragments }\right]}+I_{[\text {Reduced_Precursor__on }]}} \times 100 \%
\end{aligned}
$$

where $\Sigma \mathrm{I}_{\left[\mathrm{ECD}_{-} \text {Fragments] }\right.}$ represents the sum of intensities of ECD induced fragments, which include typical $c$ - and $z$-ions, $[c-H]^{\bullet}$ and $[\mathrm{z}+\mathrm{H}]$ ions, side-chain loss from $\mathrm{z}_{\mathrm{n}}{ }^{+} \bullet$ and peaks related to $[\mathrm{M}+2 \mathrm{H}]^{+\bullet}$ and $I_{\text {[Reduced_Precursor_Ion] }}$ represent the reduced precursor ion intensity. Figure $2 \mathrm{~b}$ summarizes the calculated $\mathrm{ECD}_{\text {Pro_Disso }}$ values of $[\mathrm{M}+$ $2 \mathrm{H}]^{2+}$ of diarginated model peptides. From the three replicate measurements, the error of $\mathrm{ECD}_{\text {Pro_Disso }}$ of RGEGNGEGEGNGEGR was found to be $\pm 0.9 \%$. Probability for dissociation in ECD of $[\mathrm{M}+2 \mathrm{H}]^{2+}$ was found to decrease progressively as the number of $\mathrm{E}$ and $\mathrm{N}$ residues increases. A strong suppression of fragmentation was observed for the model peptides with $6 \mathrm{E}$ $($ or $4 \mathrm{E}+2 \mathrm{~N}$ ) residues. This trend is rather similar to the result of $\mathrm{H}^{\bullet}$ loss from $[\mathrm{M}+2 \mathrm{H}]^{+\bullet}$ as shown in Figure 2a.

$$
\text { ECD of }[M+2 H]^{2+} \text { Versus }[M+3 H]^{3+}
$$

Figure $3(\mathrm{a}-\mathrm{c})$ show typical ECD spectra of triplyprotonated model peptide ions, $[\mathrm{M}+3 \mathrm{H}]^{3+}$, with the sequences of RGGGGEGGGEGGGGR, RGEGGEG- 


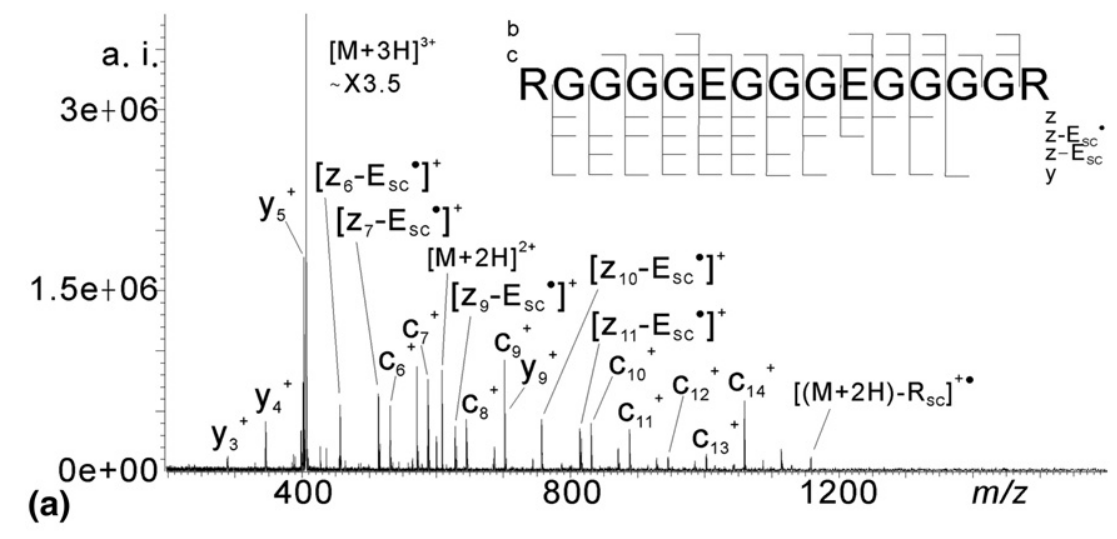

(a)
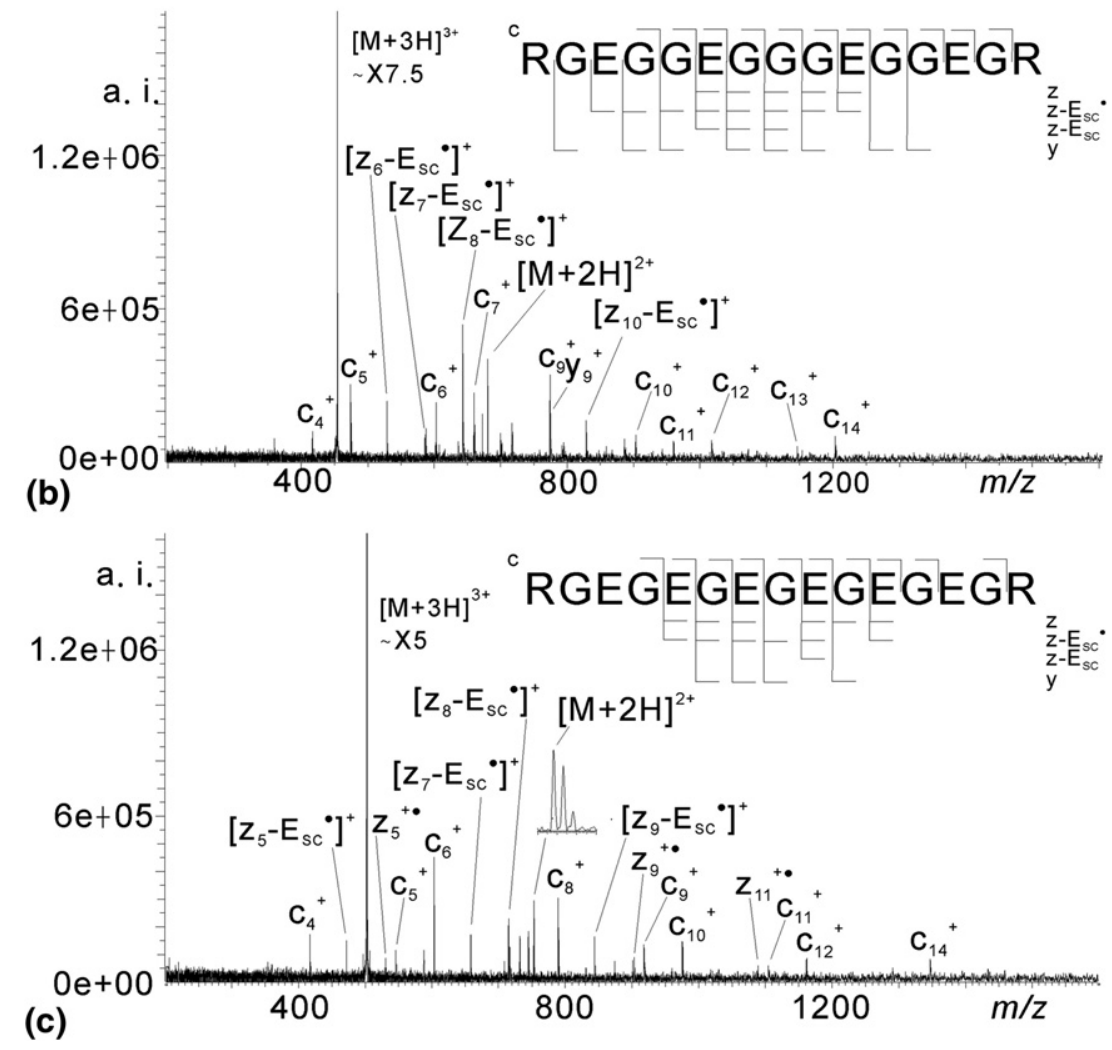

Figure 3. Typical ECD spectra of $[\mathrm{M}+3 \mathrm{H}]^{3+}$ where $\mathrm{M}$ is (a) RGGGGEGGGEGGGGR, (b) RGEGGEGGGEGGEGR, and (c) RGEGEGEGEGEGEGR.

GGEGGEGR, and RGEGEGEGEGEGEGR, respectively. Typical ECD fragments, i.e., $\mathrm{C}_{3}{ }^{+}$to $\mathrm{C}_{14}{ }^{+}, \mathrm{z}_{4}{ }^{+}{ }^{+}$to $\mathrm{z}_{14}{ }^{+} \cdot \mathrm{e}, \mathrm{E}$ side-chain loss from $z$-ions and peaks correspond to charge-reduced precursor ion $\left([\mathrm{M}+3 \mathrm{H}]^{2+}\right)$ were observed. No $[\mathrm{c}-\mathrm{H}]^{\bullet},[\mathrm{z}+\mathrm{H}]$, and double-electron reduced precursor ions $\left([\mathrm{M}+3 \mathrm{H}]^{+\bullet}\right)$ were found in these spectra. Some complementary $c$ - and $z$-ion pairs were also observed, including $\mathrm{c}_{5}{ }^{+} / \mathrm{z}_{10}{ }^{+\bullet}, \mathrm{c}_{6}{ }^{+} / \mathrm{z}_{9}{ }^{+\bullet}$, $\mathrm{c}_{7}{ }^{+} / \mathrm{z}_{8}{ }^{+}, \mathrm{c}_{8}{ }^{+} / \mathrm{z}_{7}{ }^{+}$, , and $\mathrm{c}_{9}{ }^{+} / \mathrm{z}_{6}{ }^{+} \bullet$. More peaks related to $E$ side-chain loss (both odd- or even-electron) from $z$-ions were observed for peptides with higher number of $\mathrm{E}$ residues. Besides typical ECD backbone fragments $c$ - and $z$-ions, $b$ - and $y$-ions produced by non-standard ECD channel(s) were also found. The extent of nonstandard ECD cleavages was found to reduce as the number of $\mathrm{E}$ increases. In contrast to their doublyprotonated peptides as shown in Figure 1, the extent of backbone cleavages in Figure 3 were less dependence of the number of $\mathrm{E}$ residues. Comparing Figure 1c and Figure $3 \mathrm{c}, \mathrm{ECD}$ of $[\mathrm{M}+2 \mathrm{H}]^{2+}$ shows suppression of backbone fragments, whereas ECD of $[\mathrm{M}+3 \mathrm{H}]^{3+}$ gives many backbone fragments. Besides suppression of backbone cleavages, percentage of $\mathrm{H}^{\bullet}$ loss from the reduced precursor ion in triply-protonated diarginated E-rich peptide ions was much higher than that in its corresponding doubly-protonated peptide ions as shown in Figure 1c and Figure 3c. Although the relative percentage of loss of hydrogen atom from the ECD of $[\mathrm{M}+2 \mathrm{H}]^{2+}$ and $[\mathrm{M}+3 \mathrm{H}]^{3+}$ is in line with the charge-state effect as demonstrated previously by $\mathrm{K}$. 


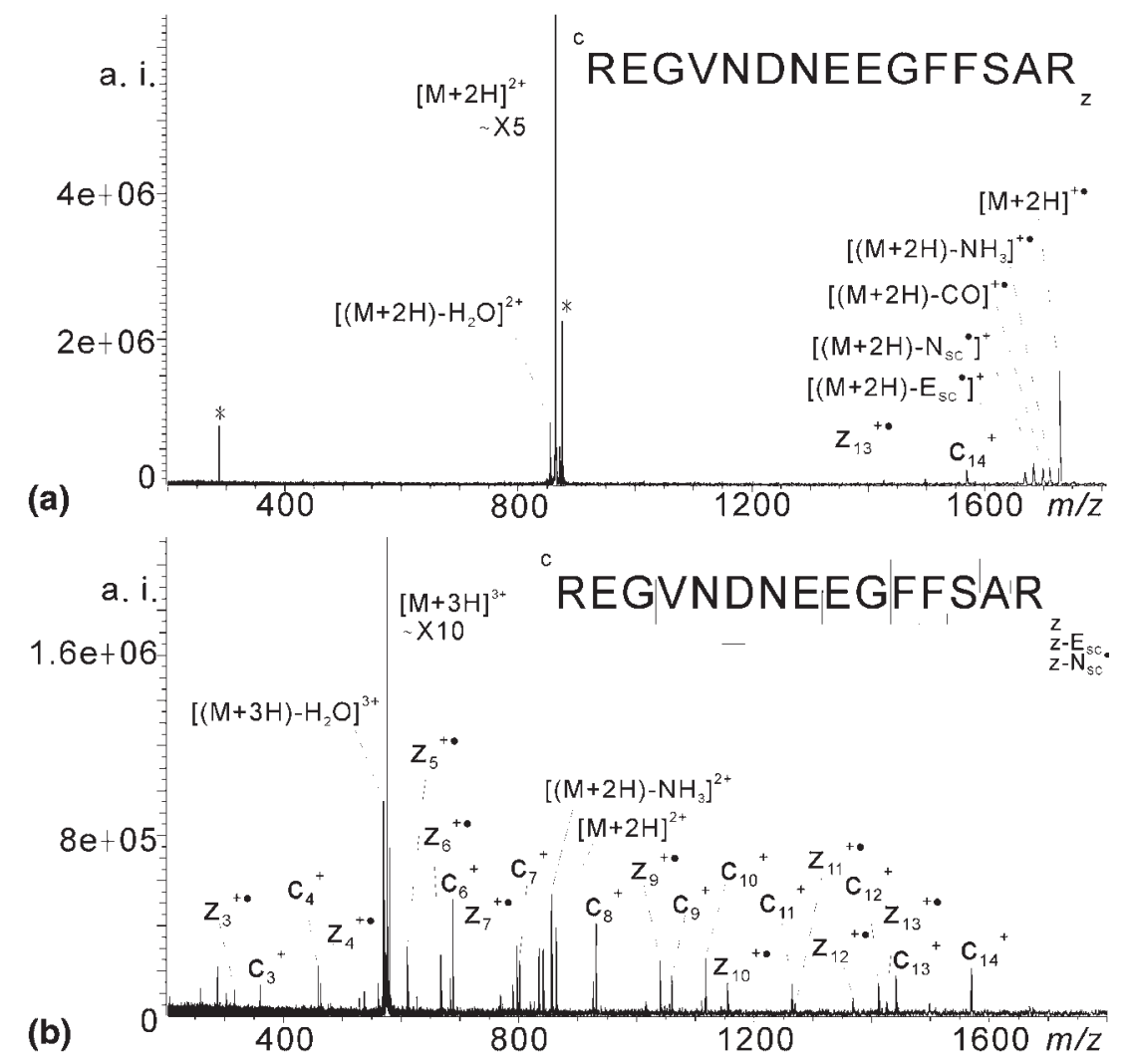

Figure 4. Typical ECD spectra of $[\mathrm{M}+2 \mathrm{H}]^{2+}$ and $[\mathrm{M}+3 \mathrm{H}]^{3+}$ where $\mathrm{M}$ is $\mathrm{N}$-arginated fibrinopeptide-B.

Breuker et al. [32], using $7+$ to $13+$ of ubiquitin ions, the charge-state effect could not be used to explain the concurrent suppression of backbone cleavages in the case of $[\mathrm{M}+2 \mathrm{H}]^{2+}$. More experiments were needed to ascertain the origin(s) of these suppression effects.

\section{Fibrinopeptide-B and Its Analogues}

The suppression of backbone cleavages obtained using these model peptides were reconfirmed by analyzing N-arginated Fibrinopeptide-B (i.e., REGVNDNEEGFFSAR). This peptide contains four acidic residues (i.e., $3 \mathrm{E}$ and $1 \mathrm{D})$ and $2 \mathrm{~N}$ residues. Figure 4 shows ECD spectra of doubly- and triply-protonated N-arginated Fibrinopeptide- $\mathrm{B}$ molecules. ECD of $[\mathrm{M}+2 \mathrm{H}]^{2+}$ species generates predominantly $[\mathrm{M}+2 \mathrm{H}]^{+\bullet}$, whereas ECD of $[\mathrm{M}+3 \mathrm{H}]^{3+}$ species leads to extensive backbone cleavages. These results resemble those of diarginine model peptide with $6 \mathrm{E}$ as shown in Figure 1c and Figure 3c. The importance of arginine residue as proton carrier was revealed by examining the ECD behaviors of fibrinopeptide-B (EGVNDNEEGFFSAR) and its analogue (REGVNDNEEGFFSA). Figure $5 a$ and $b$ show the ECD of doubly-protonated EGVNDNEEGFFSAR and REGVNDNEEGFFSA. In contrast to Figure 4a, ECD of doubly-protonated EGVNDNEEGFFSAR and REGVNDNEEGFFSA show extensive backbone cleavages leading to series of $z$-ions and $c$-ions, respectively. The role of arginine residue as charge carrier on the cleavage suppression is not known. The absence of suppression effect in these doubly-protonated monoarginated peptides and the triply-protonated diarginated model peptides (see Figure 3) is interesting. Empirically, tight holding of protons by arginine residues seems to be one of the prerequisites for strong suppression of backbone cleavage and $\mathrm{H}^{\bullet}$ loss from $[\mathrm{M}+2 \mathrm{H}]^{+\bullet}$. Further experiments are now in progress to address this issue.

\section{Structural Motif that Suppresses Backbone Cleavages in Diarginated E-Rich Peptides}

There exist two possible scenarios to account for the suppression of ECD cleavages in the ECD experiments of diarginated E-rich peptides. The charge-reduced precursor ions, $[\mathrm{M}+2 \mathrm{H}]^{+}$, formed under typical ECD conditions might undergo usual cleavages to form $c-/ z^{\bullet}$-fragments. However, these $c-/ z^{\bullet}$-fragments might be held together for an extended period of time (beyond the time-scale of typical FTICR excitation and detection events) by strong and/or multiple hydrogen bonds. Therefore, $[\mathrm{M}+2 \mathrm{H}]^{+}$' was observed instead of backbone fragments. Another possible scenario is that the $[\mathrm{M}+2 \mathrm{H}]^{+}$formed was somehow stabilized and the usual backbone cleavage channels were inhibited. A possible way to differentiate these two scenarios is to investigate the dissociation behavior of the chargereduced precursor ions upon additional activation. 


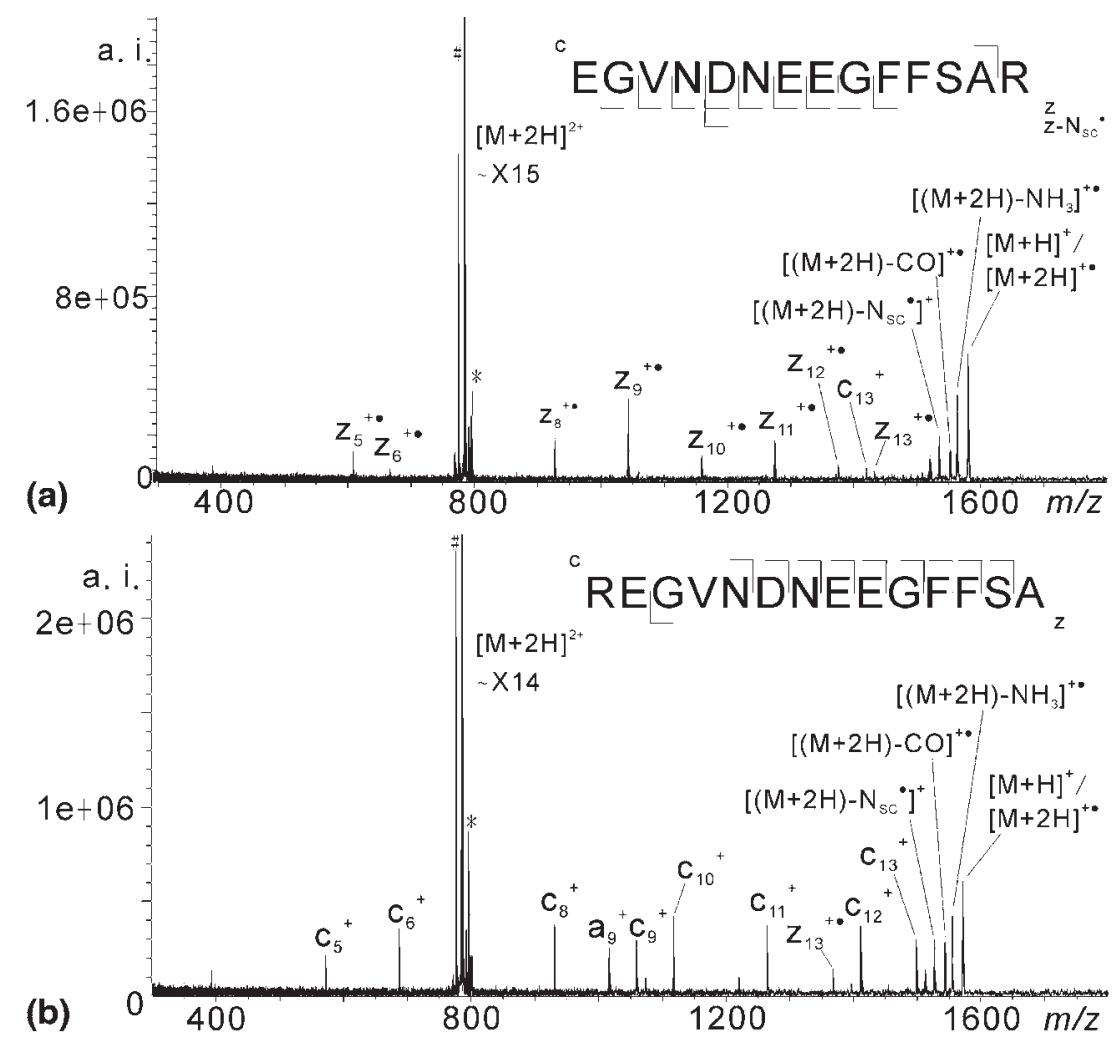

Figure 5. Typical ECD spectra of $[\mathrm{M}+2 \mathrm{H}]^{2+}$ where $\mathrm{M}$ is (a) EGVNDNEEGFFSAR and (b) REGVNDNEEGFFSA. ${ }^{*}$ Indicates $\left[(\mathrm{M}+2 \mathrm{H})-\mathrm{H}_{2} \mathrm{O}\right]^{2+}$

Table 1 shows the ECD spectra of doubly-protonated RGEGEGEGEGEGEGR obtained (i) under typical ECD conditions; (ii) with an extended time delay ( $3 \mathrm{~s}$ ) after the electron irradiation before the ion excitation and detection; and (iii) with subsequent pulsing of inert gas $(1.2 \mathrm{~ms})$ after the electron irradiation event and followed with a delay (3 s). Typical ECD experiment generates only a few backbone fragments; and the loss of $\mathrm{H}^{\bullet}$ from $[\mathrm{M}+2 \mathrm{H}]^{+}$' was largely suppressed (see Table 1i). Consistent with the expectation, insertion of a long delay after the electron capture event allows metastable dissociation of the charge-reduced precursor ions (see Table $1 \mathrm{ii}$ ). It is important to note that only $b$ and $y$-ions were observed in this case and the typical $c-/ z^{\bullet}$-fragments were largely suppressed (data of $b$ - and $y$-ions are not shown). Temporary elevation of the cell pressure by pulsing argon gas into the trapped ion cell after the electron irradiation event has significant impact of the associated ECD spectrum (see Table 1 iii). Apart from the expected $b$ - and $y$-ions, several $c$ - and $z^{\circ}$ fragment ions were generated. In addition, a high percentage of the charge-reduced precursor ions were also found to lose $\mathrm{H}^{\cdot}$ to form $[\mathrm{M}+\mathrm{H}]^{+}$ions. The experimental findings support a notion that the capture of a low-energy electron by the doubly-protonated RGEGEGEGEGEGEGR ion liberates recombination energy; and this energy randomizes along different degrees of freedom and finally invokes the usual $\mathrm{C}-\mathrm{N}$ cleavages through the mobile proton channels. The radical initiated cleavage channels were largely inhibited in the ECD of diarginated E-rich peptide ions. The charge-reduced precursor ions, $[\mathrm{M}+2 \mathrm{H}]^{+}{ }^{\bullet}$, produced remain largely intact. However, the inhibition factor (see below for discussion) was somehow lifted through collisions with inert gas molecules. Both $\mathrm{N}-\mathrm{C}_{\alpha}$ cleavage and $\mathrm{H}^{\bullet}$ loss channels were activated leading to the generation of additional $c^{-}, z^{-}-$, and $[\mathrm{M}+\mathrm{H}]^{+}$fragment ions.

To gain additional insight into the suppression effect, conformational search of the doubly-protonated RGEGEGEGEGEGEGR was performed to extract the conformational features of the low-energy structures. To avoid the lengthy process of computing and comparing the exact energies of various forms of this peptide, the zwitterion form of this peptide was taken as the predominant species based on several literature studies involving systems with similar functions. For instance, Rodriquez et al. performed detailed computational analysis of gaseous bradykinin (BK) at different charge states [33]. Similar to our model peptide, BK has arginine residues $(\mathrm{R})$ at both termini. For doublyprotonated bradykinin, $[\mathrm{BK}+2 \mathrm{H}]^{2+}$, zwitterion form was found to have lower energy than that of canonical form. For peptides containing acidic residues, $\mathrm{Li}$ and coworkers [34] found that deprotonation of the main chain C-terminal carboxylic group is preferred over the side-chain carboxylic group. Details of the calculation results are included in the Supplementary Information 
Table 1. Summary of fragment peaks of [RGEGEGEGEGEGEGR $+2 \mathrm{H}]^{2+}$ (i) under typical ECD conditions; (ii) with an extended time delay $(3 \mathrm{~s})$ after the electron irradiation prior to the ion excitation and detection; and (iii) with subsequent pulsing of inert gas after the electron irradiation event and followed with a 3 s delay

Relative intensities $(\%)^{\mathrm{c}}$

\begin{tabular}{|c|c|c|c|c|}
\hline Assignment & Theoretical mass & (i) Normal ECD & (ii) ECD with delay ${ }^{a}$ & $\begin{array}{l}\text { (III) ECD with Pulse gas } \\
\text { and delay }{ }^{b}\end{array}$ \\
\hline$[\mathrm{M}+2 \mathrm{H}]^{2+}$ & 752.8166 & 100.00 & 100.00 & 100.00 \\
\hline$\left[(\mathrm{M}+2 \mathrm{H})^{-} \mathrm{H}_{2} \mathrm{O}\right]^{2+}$ & 743.8113 & 1.07 & - & 1.07 \\
\hline$[\mathrm{M}+2 \mathrm{H}]^{+\bullet}$ & 1505.6331 & 2.96 & 1.11 & 0.81 \\
\hline$[\mathrm{M}+\mathrm{H}]^{+}$ & 1504.6258 & - & - & 0.56 \\
\hline$\left[(\mathrm{M}+2 \mathrm{H})^{-} \mathrm{NH}_{3}\right]^{+}$ & 1488.6066 & 0.85 & 0.37 & 0.47 \\
\hline$\left[(\mathrm{M}+2 \mathrm{H})^{-} \mathrm{CO}\right]^{+\bullet}$ & 1477.6382 & 1.69 & 0.63 & 0.49 \\
\hline$\left[(\mathrm{M}+\mathrm{H})^{-} \mathrm{CO}_{2}\right]^{+}$ & 1460.6360 & 0.11 & - & - \\
\hline$\left[(\mathrm{M}+2 \mathrm{H})^{-\bullet} \mathrm{CH}_{2} \mathrm{COOH}\right]^{+}[\mathrm{E}]$ & 1446.6198 & 0.17 & 0.17 & 0.23 \\
\hline$\left[(\mathrm{M}+2 \mathrm{H})^{-} \mathrm{CH}_{2} \mathrm{CHCOOH}\right]^{+}[\mathrm{E}]$ & 1433.6120 & 0.27 & 0.17 & 0.20 \\
\hline $\mathrm{c}_{14}+/\left[\mathrm{c}_{14}{ }^{-} \mathrm{H}\right]^{+\bullet}$ & $1347.5407 / 1346.5334$ & $0.65 / 0.49$ & $0.31 / 0.18$ & $1.32 / 0.44$ \\
\hline $\mathrm{c}_{13}{ }^{+} /\left[\mathrm{c}_{13}{ }^{-} \mathrm{H}\right]^{+\bullet}$ & $1290.5192 / 1289.5120$ & $0.17 / 0.28$ & $0.18 / 0.14$ & $-/ 0.52$ \\
\hline $\mathrm{c}_{12}{ }^{+} /\left[\mathrm{c}_{12}{ }^{-} \mathrm{H}\right]^{+\bullet}$ & $1161.4766 / 1160.4694$ & $0.20 / 0.25$ & $0.12 / 0.30$ & $0.40 / 0.62$ \\
\hline $\mathrm{C}_{11}{ }^{+}-\mathrm{H}^{\bullet}$ & 1103.4479 & - & - & 0.37 \\
\hline $\mathrm{c}_{10}{ }^{+} /\left[\mathrm{c}_{10}{ }^{-} \mathrm{H}\right]^{+\bullet}$ & $975.4126 / 974.4053$ & $0.16 / 0.26$ & $0.18 /-$ & $0.49 / 0.67$ \\
\hline $\mathrm{c}_{9}^{+} /\left[\mathrm{c}_{9}{ }^{-} \mathrm{H}\right]^{+\bullet}$ & $918.3911 / 917.3839$ & $0.28 / 0.35$ & $0.15 / 0.25$ & $0.33 / 0.42$ \\
\hline $\mathrm{c}_{8}{ }^{+} /\left[\mathrm{c}_{8}{ }^{-} \mathrm{H}\right]^{+\bullet}$ & $789.3485 / 788.3413$ & $0.44 / 0.48$ & $0.17 / 0.35$ & $0.41 / 0.95$ \\
\hline $\mathrm{C}_{7}^{+}-\mathrm{H}^{\bullet}$ & 731.3198 & - & - & 0.33 \\
\hline $\mathrm{c}_{6}{ }^{+}-\mathrm{H}^{\bullet}$ & 602.2772 & - & - & 0.51 \\
\hline 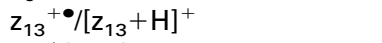 & $1275.4845 / 1276.4918$ & -10.20 & $-/ 0.23$ & $0.44 / 1.01$ \\
\hline $\mathrm{z}_{12}+\bullet+\mathrm{H}^{\bullet}$ & 1147.4492 & - & - & 0.53 \\
\hline $\mathrm{z}_{11}^{+\bullet}+\mathrm{H}^{\bullet}$ & 1090.4278 & - & - & 0.77 \\
\hline $\mathrm{z}_{10}^{+\bullet}+\mathrm{H}^{\bullet}$ & 961.3852 & - & - & 0.24 \\
\hline
\end{tabular}

aThe extended time delay after the electron irradiation prior to the ion excitation and detection is $3 \mathrm{~s}$.

bWith subsequent pulsing of inert gas $(1.2 \mathrm{~ms})$ after the electron irradiation event and followed with a $3 \mathrm{~s}$ delay.

$\mathrm{c} b / y$ Fragment ions were excluded from this table for clarity purposes.

(Table S1, which can be found in the electronic version of this article).

Figure 6 shows the lowest energy zwitterion structure of [RGEGEGEGEGEGEGR $+2 \mathrm{H}]^{2+}$ obtained by conformational search. For clarity purposes, only hydrogen atoms that are capable of forming classical hydrogen bonds are shown. Hydrogen bonds between carbonyl oxygen of $\mathrm{E}$ side chain and backbone amide

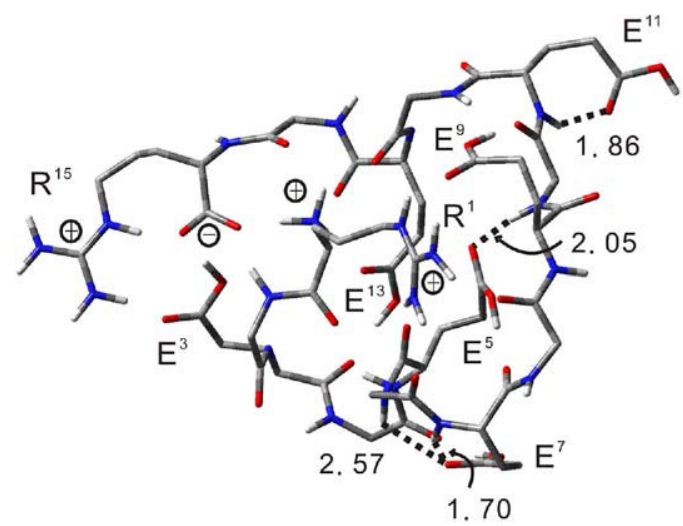

Figure 6. The lowest energy zwitterion structures of [RGEGEGEGEGEGEGR $+2 \mathrm{H}]^{2+}$ obtained by conformational search. For clarity, only hydrogen atoms of importance to the structure are shown. Hydrogen bonds between carbonyl oxygen of E side-chain and backbone amide hydrogen are illustrated by dotted lines. The distances are in angstroms. hydrogen are illustrated by dotted lines. In Figure 6, salt bridge was formed between C-terminal carboxylate anion and N-terminal protonated amine. The formation of this salt-bridge structure is in agreement with the previous theoretical studies on the lowest energy structures of doubly-protonated bradykinin species [32]. The two protonated arginine side chains were mainly solvated by backbone carbonyl groups, four hydrogen bonds were formed between carbonyl oxygen of E side chains and backbone amide hydrogen atoms. These hydrogen bonds were believed to serve as inhibiting factors to suppress the usual $\mathrm{N}-\mathrm{C}_{\alpha}$ cleavages. Scheme $\mathbf{1}$ shows a proposed pathway for suppression of backbone cleavages in these diarginated E-rich peptides. Besides inducing $\mathrm{N}-\mathrm{C}_{\alpha}$ cleavage, abstraction of $\mathrm{H}^{\bullet}$ from guanidine group to backbone carbonyl oxygen might lead to hydrogen transfer from backbone amide nitrogen to carbonyl oxygen of E side chain. The hydrogen bonds formed between the carbonyl oxygen of E side chains and backbone amide hydrogen atoms could inhibit the usual $\mathrm{N}-\mathrm{C}_{\alpha}$ cleavages by resonantly stabilizing the radical intermediate. As a result, the chargereduced precursor ion would remain intact as no backbone linkage would be cleaved. Upon collisional activation, the charge-reduced precursor could be activated and undergo further dissociation through two alternative pathways, including $\mathrm{H}^{\bullet}$ loss from $[\mathrm{M}+$ $2 \mathrm{H}]^{+}$and $\mathrm{N}-\mathrm{C}_{\alpha}$ cleavage. Therefore, when argon gas 


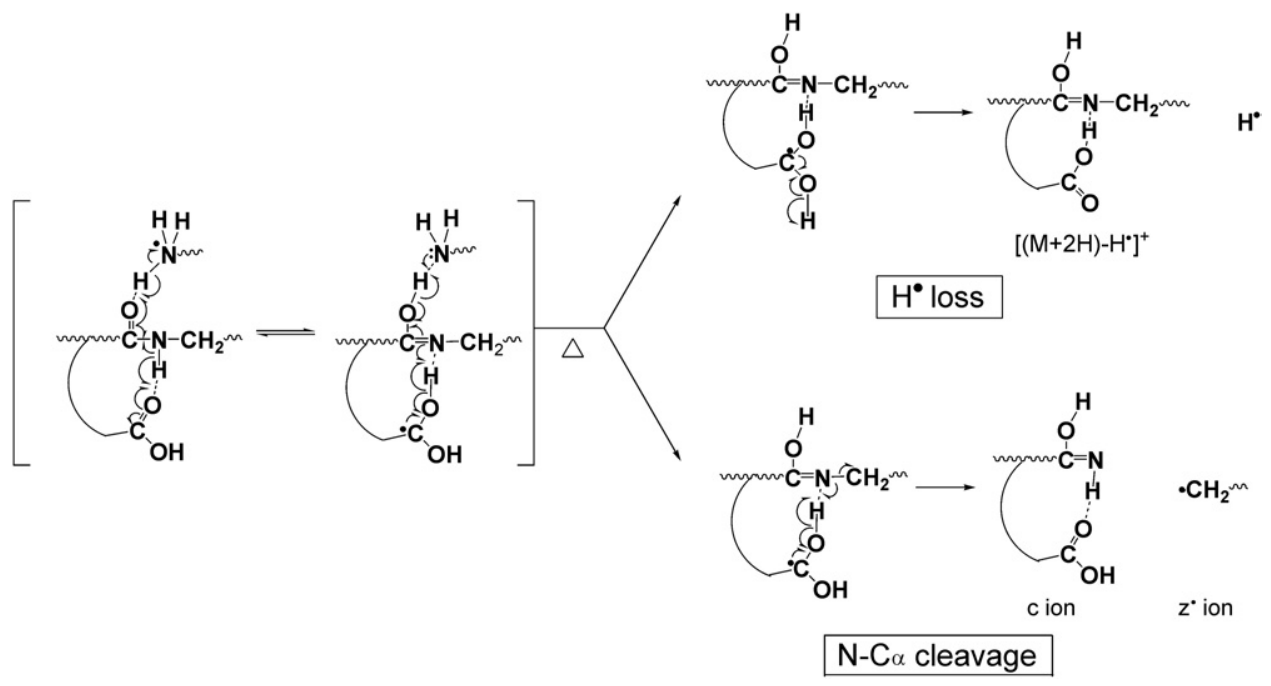

Scheme 1. A possible mechanism to account for the stabilization of $[\mathrm{M}+2 \mathrm{H}]^{+} \cdot$ by the interactions between carbonyl oxygen of $\mathrm{E}$ side-chain and backbone amide hydrogen.

was pulsed into the cell after ECD, a few more $c$ - and $z$-ions were produced and $[\mathrm{M}+\mathrm{H}]^{+}$was observed.

\section{Conclusion}

Through the study of a series of diarginated model peptides with different number of glutamic acid (E) and asparagine $(\mathrm{N})$ residues, suppression of backbone cleavage and loss of hydrogen atom $\left(\mathrm{H}^{\circ}\right)$ from the reduced precursor ions $\left([\mathrm{M}+2 \mathrm{H}]^{+}{ }^{\bullet}\right)$ were first observed. ECD spectra of doubly-protonated peptides show a strong dependence on the number of $\mathrm{E}$ and $\mathrm{N}$ residues. Apparently, both the backbone cleavages and $\mathrm{H}^{\bullet}$ loss from $[\mathrm{M}+2 \mathrm{H}]^{+}$' were suppressed as the number of $\mathrm{E}$ and $\mathrm{N}$ residues increases. A strong inhibition of the backbone cleavages and $\mathrm{H}^{\bullet}$ loss was found for peptides with $6 \mathrm{E}$ residues (or $4 \mathrm{E}+2 \mathrm{~N}$ residues). The results obtained using these model peptides were re-confirmed by analyzing $\mathrm{N}$-arginated FibrinopeptideB (i.e., REGVNDNEEGFFSAR). ECD of the triplyprotonated peptides leads to extensive backbone cleavages; whereas ECD of the doubly-protonated species generates predominantly charge-reduced precursor ions. Based on these data, it is believed that peptide ions with all surplus protons sequestered in arginine residues would show enhanced stability under ECD conditions as the number of acid-residue increases. A possible hypothesis for the suppression of backbone cleavages and $\mathrm{H}^{\bullet}$ loss from $[\mathrm{M}+2 \mathrm{H}]^{+}$is related to the presence of alternative dissociation pathways apart from the usual $\mathrm{N}-\mathrm{C}_{\alpha}$ cleavages. From the lowest-energy structure of diarginated E-rich peptides, interactions between carbonyl oxygen of E side chains and hydrogen of backbone amides were found. It is tentatively believed that these hydrogen bonds could inhibit the usual $\mathrm{N}-\mathrm{C}_{\alpha}$ cleavages and $\mathrm{H}^{\bullet}$ loss by resonantly stabilizing the radical intermediate as shown in Scheme $\mathbf{1 .}$ When the charge-reduced precursor ion was activated, it can further dissociate through two alternative pathways, including $\mathrm{N}-\mathrm{C}_{\alpha}$ cleavages or $\mathrm{H}^{\bullet}$ loss from reduced precursor.

\section{Acknowledgments}

The authors thank Li Kwok Chun for MacroModel analysis. The authors gratefully acknowledge that the work described in this paper was supported by a grant (no. CUHK400207) from the Research Grants Council of the Hong Kong Special Administrative Region, China.

\section{Appendix A Supplementary Material}

Supplementary material associated with this article may be found in the online version at doi:10.1016/ j.jasms.2010.03.034.

\section{References}

1. Zubarev, R. A.; Kelleher, N. L.; McLafferty, F. W. Electron Capture Dissociation of Multiply Charged Protein Cations. A Nonergodic Process. J. Am. Chem. Soc. 1998, 120, 3265-3266.

2. Zubarev, R. A.; Horn, D. M.; Fridriksson, E. K.; Kelleher, N. L.; Kruger, N. A.; Lewis, M. A.; Carpenter, B. K.; McLafferty, F. W. Electron Capture Dissociation for Structural Characterization of Multiply Charged Protein Cations. Anal. Chem. 2000, 72, 563-573.

3. Ge, Y.; Lawhorn, B. G.; ElNaggar, M.; Strauss, E.; Park, J. H.; Begley, T. P.; McLafferty, F. W. Top Down Characterization of Larger Proteins (45 kDa) by Electron Capture Dissociation Mass Spectrometry. J. Am. Chem. Soc. 2002, 124, 672-678.

4. Zubarev, R. A.; Haselmann, K. F.; Budnik, B.; Kjeldsen F.; Jensen, F. Towards an Understanding of the Mechanism of Electron-Capture Dissociation: A Historical Perspective and Modern Ideas. Eur. J. Mass Spectrom. 2002, 8, 337-349.

5. Stensballe, A.; Jensen, O. N.; Olsen, J. V.; Haselmann, K. F.; Zubarev, R. A. Electron Capture Dissociation of Singly and Multiply Phosphorylated Peptides. Rapid Commun. Mass Spectrom. 2000, 14, 1793-1800.

6. Mirgorodskaya, E.; Roepstorff, P.; Zubarev, R. A. Localization of O-Glycosylation Sites in Peptides by Electron Capture Dissociation in a Fourier Transform Mass Spectrometer. Anal. Chem. 1999, 71, 4431-4436.

7. Guan, Z.; Yates, N. A.; Bakhtiar, R. Detection and Characterization of Methionine Oxidation in Peptides by Collision-Induced Dissociation and Electron Capture Dissociation. J. Am. Soc. Mass Spectrom. 2003, 14, 605-613. 
8. Medzihradszky, K. F.; Gillece-Castro, B. L.; Townsend, R. R.; Burlingame, A. L. Structural Elucidation of O-Linked Glycopeptides by High Energy Collision-Induced Dissociation. J. Am. Soc. Mass Spectrom. 1996, 7, 319-328.

9. Flora J. W.; Muddiman, D. C. Selective, Sensitive, and Rapid Phosphopeptide Identification in Enzymatic Digests Using ESI-FTICR-MS with Infrared Multiphoton Dissociation. Anal. Chem. 2001, 73, 33053311.

10. Cody, R. B.; Frelser, B. S. Collision-Induced Dissociation with Fourier Transform Mass Spectrometry. Anal. Chem. 1982, 54, 96-101.

11. Biemann, K. Sequencing of Peptides by Tandem Mass Spectrometry and High-Energy Collision-Induced Dissociation. Methods Enzymol. 1990, 193, 455-479.

12. Senko, M. W.; Speir, J. P.; McLafferty, F. W. Collisional Activation of Large Multiply Charged Ions Using Fourier Transform Mass Spectrometry. Anal. Chem. 1994, 66, 2801-2808.

13. Little, D. P.; Speir, P.; Senko, M. W.; O'Connor, P. B.; McLafferty, F. W. Infrared Multiphoton Dissociation of Large Multiply Charged Ions for Biomolecules Sequencing. Anal. Chem. 1994, 66, 2809-2815.

14. Zubarev, R. A.; Kruger, N. A.; Fridriksson, E. K.; Lewis, M. A.; Horn, D. M.; Carpenter, B. K.; McLafferty, F. W. Electron Capture Dissociation of Gaseous Multiply-Charged Proteins is Favored at Disulfide Bonds and Other Sites of High Hydrogen Atom Affinity. J. Am. Chem. Soc. 1999, 121, 2857-2862.

15. Leymarie, N.; Berg, E. A.; McComb, M. E.; O'Connor, P. B.; Grogan, J.; Oppenheim, F. G.; Costello, C. E. Tandem Mass Spectrometry for Structural Characterization of Proline-Rich Proteins: Application to Salivary PRP-3. Anal. Chem. 2002, 74, 4124-4132.

16. Belyayev, M. A.; Cournoyer, J. J.; Lin, C.; O'Connor, P. B. The Effect of Radical Trap Moieties on Electron Capture Dissociation Spectra of Substance P. J. Am. Soc. Mass Spectrom. 2006, 17, 1428-1436.

17. Jones, J. W.; Sasaki, T.; Goodlett, D. R.; Turecek, F. Electron Capture in Spin-Trap Capped Peptides. An Experimental Example of Ergodic Dissociation in Peptide Cation-Radicals. J. Am. Soc. Mass Spectrom. 2007, 18, 432-444

18. Li, X. J.; Cournoyer, J. J.; Lin, C.; O'Connor, P. B. The Effect of Fixed Charge Modifications on Electron Capture Dissociation. J. Am. Soc. Mass Spectrom. 2008, 19, 1514-1526.

19. Chamot-Rooke, J.; Malosse, C.; Frison, G.; Turecek, F. Electron Capture in Charge-Tagged Peptides. Evidence for the Role of Excited Electronic States. J. Am. Soc. Mass Spectrom. 2007, 18, 2146-2161.

20. Mihalca, R.; Kleinnijenhuis, A. J.; McDonnell, L. A.; Heck, A. J. R.; Heeren, R. M. A. Electron Capture Dissociation at Low Temperatures Reveals Selective Dissociations. J. Am. Soc. Mass Spectrom. 2004, 15, 1869-1873.

21. (a) Hongo, Y.; Nakamura, T.; Sato, A. Electron Capture Dissociation of Triantennary Complex-Type N-Glycosylated Peptides: A Case of Suppressed Peptide Backbone Cleavage. J. Mass Spectrom. Soc. Jpn. 2007, 55,
77-82; (b) Sohn, C. H.; Chung, C. K.; Yin, S.; Ramachandran, P.; Loo, J. A.; Beauchamp, J. L. Probing the Mechanism of Electron Capture and Electron Transfer Dissociation Using Tags with Variable Electron Affinity. J. Am. Chem. Soc. 2009, 131, 5444-5459.

22. Chan, W. C.; White, P. D. FMOC Solid Phase Peptide Synthesis: A Practical Approach; Oxford University Press: New York, 2000; pp 41-74.

23. Taralp, A.; Türkseven, C. H.; Cakamk, A. Ö.; Cengel, Ö. Introducing Freshmen Students to the Practice of Solid-Phase Synthesis J. Chem. Educ. 2002, 79, 87-89.

24. Bacsa, B.; Desai, B.; Dibo, G.; Kappe, C. O. Rapid Solid-Phase Peptide Synthesis Using Thermal and Controlled Microwave Irradiation. J. Pept. Sci. 2006, 12, 633-638.

25. Fong, K. W. Y.; Chan, T.-W. D A Novel Nonmetallized Tip for Electrospray Mass Spectrometry at Nanoliter Flow Rate. J. Am. Soc. Mass Spectrom. 1999, 10, 72-75

26. Caravatti, P.; Allemann, M. The Infinity Cell: A New Trapped-Ion Cell with Radiofrequency Covered Trapping Electrodes for Fourier Transform Ion Cyclotron Resonance Mass Spectrometry. Org. Mass Spectrom. 1991, 26, 514-518.

27. Sze, T. P. E. Development of New Methods to Perform Matrix-Assisted Laser Desorption/Ionization (MALDI) Experiments in Fourier-Transform IonCyclotron-Resonance Mass Spectrometer (FTICR-MS); Ph.D. dissertation, The Chinese University of Hong Kong, 2000.

28. Chan, T.-W. D.; Ip, W. H. H. Optimization of Experimental Parameters for Electron Capture Dissociation of Peptides in a Fourier Transform Mass Spectrometer. J. Am. Soc. Mass Spectrom. 2002, 13, 1396-1406.

29. Saunders, M.; Houk, K. N.; Wu, Y. D.; Still, W. C.; Lipton, M.; Chang, G. Guida, W. C. Conformations of Cycloheptadecane. A Comparison of Methods for Conformational Searching. J. Am. Chem. Soc. 1990, 112, 1419-1427.

30. Kolossvary, I.; Guida, W. C. Low-Mode Conformational Search Elucidated: Application to $\mathrm{C}_{39} \mathrm{H}_{80}$ and Flexible Docking of 9-Deazaguanine Inhibitors into PNP. J. Comput. Chem. 1999, 20, 1671-1684.

31. Kjeldsen, F.; Haselmann, K. F.; Budnik, B. A.; Jensen, F.; Zubarev, R. A Dissociation Capture of Hot (3-13eV) Electrons by Polypeptide Polycations: An Efficient Process Accompanied by Secondary Fragmentation. Chem. Phys. Lett. 2002, 356, 201-206.

32. Breuker, K.; Oh, H. B.; Cerda, B. A.; Horn, D. M.; McLafferty, F. W. Hydrogen Atom Loss in Electron-Capture Dissociation: A Fourier Transform-Ion Cyclotron Resonance Study with Single Isotopomeric Ubiquitin Ions. Eur. J. Mass Spectrom. 2002, 8, 177-180.

33. Rodriquez, C. F. Orlova, G.; Guo, Y. Z. Li, X. M.; Siu, C. K.; Hopkinson A. C.; Siu, K. W. M. Gaseous Bradykinin and Its Singly, Doubly, and Triply Protonated Forms: A First Principles Study. J. Phys. Chem. B 2006, 110, 7528-7537.

34. Li Z.; Matus M. H.; Velazquez, H. A.; Dixon, D. A.; Cassady, C. J. Gas-Phase Acidities of Aspartic Acid, Glutamic Acid, and Their Amino Acid Amides. Int. J. Mass Spectrom. 2007, 265, 213-223. 